\title{
Olha Já! Construção gramatical no Amazonas
}

\section{Olha já! Grammatical construction in Amazon}

Gislane Aparecida Martins SIQUEIRA*

\begin{abstract}
RESUMO: Neste trabalho, propõe-se o estudo da microconstrução amazonense olha já, apoiado teoricamente em pressupostos da Gramática de Construções, com foco especial na menção de Croft (2007) de que as estruturas sintática e semântica compõem a anatomia de uma construção podendo ser os conceitos fundamentais e os termos descritivos para a análise da estrutura de uma construção gramatical. Por meio das análises sintática e semântica se constatam a organização da composição e a compreensão global da microconstrução. Propõe-se ainda uma sugestão de sua atuação na língua. No decorrer do trabalho, constata-se no português brasileiro a existência de outras microconstruções compostas pela mesma regra da composição de olha já, o que permitiu atestar a produtividade do padrão.
\end{abstract}

PALAVRAS-CHAVE: Gramática de construções. Língua em uso. Amazonas. Estruturas sintática e semântica.

\begin{abstract}
This work proposes the study of the Amazonian microconstruction olha já, theoretically supported by assumptions of the Grammar of Constructions, with special focus on the mention of Croft (2007) that the syntactic and semantic structures make up the anatomy of a construction and they may be the fundamental concepts and the descriptive terms for the analysis of the structure of a grammatical construction. Through the syntactic and semantic analyzes, the organization of the composition and the global understanding of the micro-construction are verified. It is also proposed a suggestion for the acting of microconstruction in the language. During the work, was verified the existence of other micro-construction composed by the same rule as olha já on the Brazilian Portuguese, which allowed to attest the productivity of the standard.
\end{abstract}

KEYWORDS: Constructions grammar. Language in use. Amazon. Syntactic and semantic structures.

\footnotetext{
* Doutoranda em Estudos Linguísticos (UFMG). Docente do Instituto Federal de Educação, Ciência e Tecnologia do Amazonas (IFAM). ORCID: http://orcid.org/0000-0001-9855-3831. gislaneams@terra.com.br
} 


\section{Introdução}

Neste trabalho, apresenta-se um estudo sobre a microconstrução olha já, utilizada em conversas informais no estado do Amazonas, com o objetivo de se observar, à luz de estudiosos da Gramática de Construções, como ela se realiza em relação aos parâmetros teóricos dessa gramática.

Elege-se para estudo de olha já a Gramática de Construções, por compreender que ela oferece subsídios para descrever a forma do conhecimento linguístico do falante e por propor meios para explicar um fenômeno irregular como acontece na microconstrução, que tem em sua composição um verbo (olhar) que parece estar relacionado à visão, no entanto, na prática comunicativa seu sentido não se relaciona com o ato de ver/enxergar.

Para cumprir o objetivo proposto, apoia-se teoricamente na menção de Croft (2007) que enfatiza que as estruturas sintática e semântica compõem a anatomia de uma construção e em Boas (2013) que reconhece a importância da frequência para a contabilização da produtividade de uma construção.

Este artigo é composto por cinco seções; na primeira, tem-se a introdução; na segunda, a descrição dos pressupostos teóricos que norteiam o trabalho; na terceira, a apresentação da metodologia utilizada para análises; na quarta seção, descrevem-se as análises e seus resultados; na quinta, apresentam-se as considerações finais, reconhecendo a eficiência da análise da microconstrução por meio dos componentes que constituem a anatomia de uma construção, segundo Croft (2007).

\section{Pressupostos teóricos}

\section{1 A Gramática de Construções}

Para Goldberg (1995), na Gramática de Construções, a existência de uma construção é definida com base no preceito de que, no mínimo, uma de suas propriedades não seja previsível do conhecimento de outras construções existentes na 
gramática, ou seja: C será uma construção, se C for um par composto por forma e significado, de tal modo que alguns aspectos da forma (F), ou alguns aspectos do significado (S) não sejam estritamente previsíveis das partes componentes de $\mathrm{C}$ ou de outras construções previamente estabelecidas.

Corroborando a mencionada teoria de Goldberg, Croft (2007) reconhece que em uma construção gramatical o léxico constitui emparelhamento de forma (propriedades sintática, morfológica e fonológica) e significado (propriedades semântica, pragmática e discursiva funcional), os quais devem ser, no mínimo, parcialmente distintos e que mesmo as construções sintáticas mais gerais possuem suas correspondentes regras de interpretação semântica.

Para Croft (2007), o fornecimento de um modelo uniforme da representação gramatical, aliado à captura de uma gama mais ampla de fenômenos empíricos que a dos modelos componenciais de gramática é a grande atração da Gramática de Construções. Reconhece o elo simbólico entre a forma e o significado como a diferença essencial entre os modelos sintático componencial e construção gramatical. Entende que no modelo componencial as estruturas sintáticas são organizadas independentemente de suas correspondentes estruturas semânticas, como mostram as caixas destacadas na figura 1:

Figura 1- A relação entre forma e função em uma teoria sintática componencial.
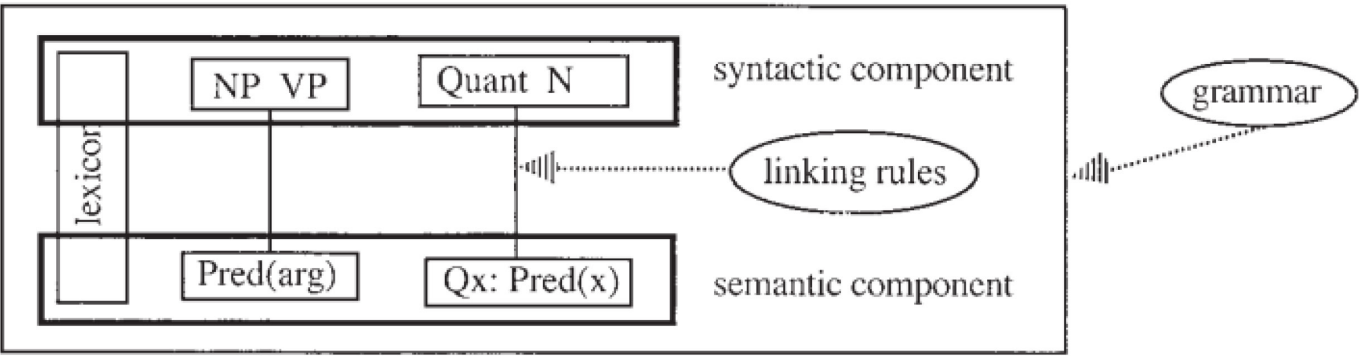

Fonte: Croft (2007, p. 473). 
Enquanto na Gramática de Construções, as unidades linguísticas básicas são simbólicas e, por isso, organizadas como unidades simbólicas, como mostram as caixas destacadas na figura 2:

Figura 2 - A relação entre forma e função em uma construção gramatical.

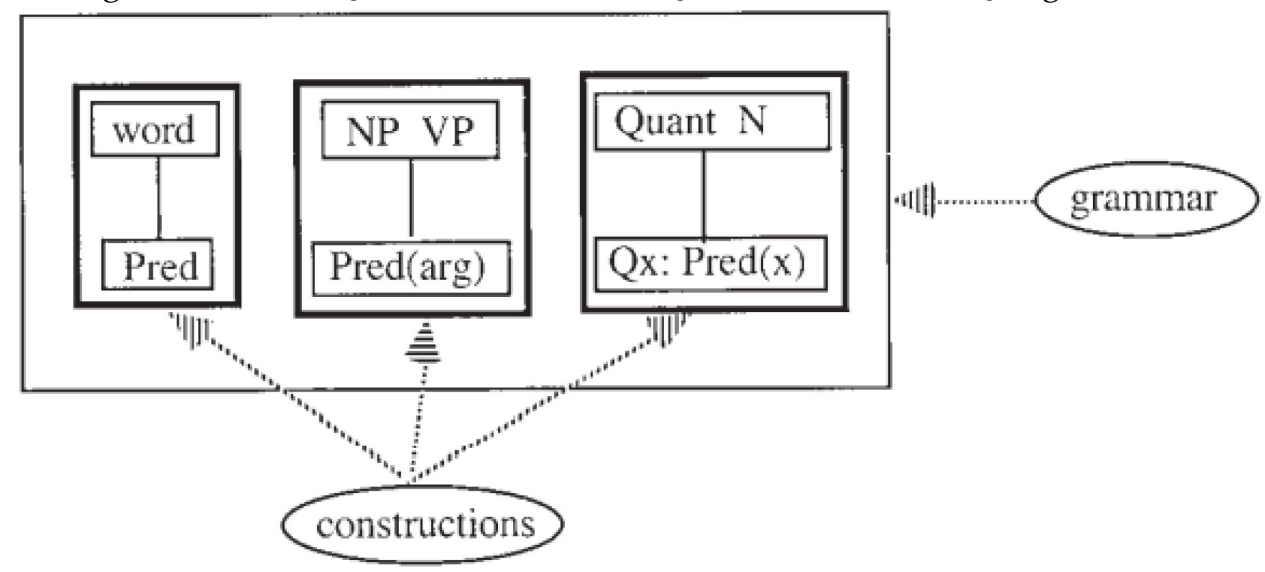

Fonte: Croft (2007, p. 473).

Como se observa na figura 2, a estrutura interna das unidades básicas na proposta da Gramática de Construções se mostra mais complexa que a do modelo sintático componencial (figura 1). Croft enfatiza que além da estrutura meronômica das unidades gramaticais, as teorias Gerativa e Gramática de Construções se divergem no ponto em que a última trata as unidades gramaticais como fundamentalmente simbólicas, ou seja, a representação de uma construção inclui relações (ligações simbólicas) de correspondência entre a forma e o significado na construção. Às partes relativas à estrutura sintática denomina de elementos e às da estrutura semântica de componentes; surgindo, com isso, um elo simbólico unindo um elemento da estrutura sintática a um componente da estrutura semântica compondo uma unidade, como o representado no esquema da construção intransitiva na figura (3): 
Figura 3 - Elemento, componente e unidade da construção.

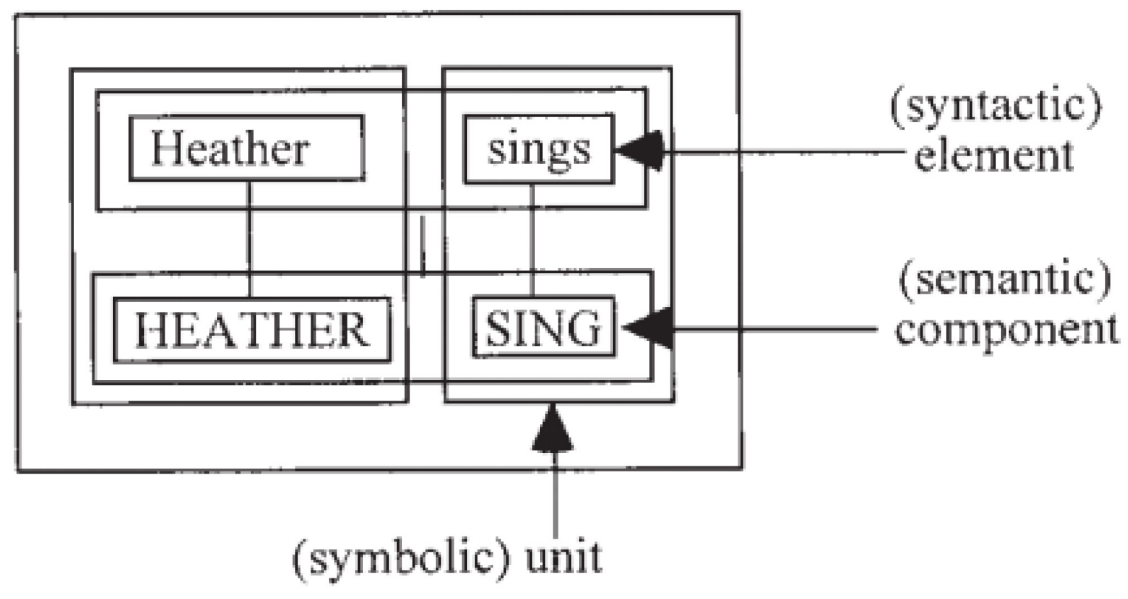

Fonte: Croft (2007, p. 476).

Croft (2007) defende que mesmo as construções sintáticas mais gerais têm correspondentes regras gerais de interpretação semântica, reconhecendo, com isso, que as estruturas sintática e semântica/significado compõem a anatomia de uma construção. Com base nesse conceito do estudioso, propõe-se, neste trabalho, as estruturas sintática e semântica/significado como conceitos fundamentais e termos descritivos para a análise da estrutura da microconstrução olha já.

Para Boas (2013), o reconhecimento das construções como emparelhamentos apreendidos de forma e significado acarreta implicações importantes para a arquitetura da gramática. O linguista corrobora a proposta de Croft (2007), ao afirmar que em uma construção, a forma pode estar associada a diferentes tipos de informações linguisticamente relevantes, reconhecendo também, que o lado formal de uma construção está ligado ao seu lado significativo por meio de um elo simbólico. Entende que o termo significado inclui aspectos convencionais associados à função de uma construção, como a omissão de determinados argumentos obrigatórios, dado o contexto apropriado do discurso ou ainda, o uso de expressão de surpresa em uma determinada situação pragmática. 


\subsection{Frequência e produtividade}

Segundo Boas (2013), dentro da Gramática de Construções, a frequência de um padrão é importante para a contabilização da produtividade de uma construção. Entende que a habilidade do falante em estender construções da estrutura do argumento a novos verbos evita a manifestação de muitas generalizações e, que a frequência determina o grau de consolidação de um esquema. Reconhece ainda, a importância de se determinar o tipo de uma construção, visto que o aumento da frequência de tipo está relacionado diretamente com a capacidade de uma construção ocorrer com novos itens.

\subsection{Atuação na língua}

Após a realização das análises sintática e semântica da microconstrução olha já, passa-se à verificação de sua atuação na língua, com base na definição de expressão idiomática de Fillmore et al (1988), ou seja, que uma expressão é considerada idiomática quando a ela é atribuída uma interpretação pela comunidade de fala. Os autores elucidam que as expressões idiomáticas podem ser de codificação ou de decodificação. Definem a expressão idiomática de decodificação como aquela que o ouvinte só consegue interpretar com total confiança se ele tiver aprendido seu significado e seu uso na prática comunicativa, dão como exemplo a expressão Kick the bucket (chutar o balde). A expressão idiomática de codificação, definem-na como uma expressão que pode ser compreendida pelo usuário da língua sem que tenha tido experiência prévia, como acontece com a expressão answer the door (atender a porta), em que o contexto da fala facilita sua compreensão.

Verifica-se ainda a atuação da microconstrução como interjeição, com base na função a ela atribuída por Cunha e Cintra (1985), que reconhecem interjeição e locução interjectiva como um grito instintivo que traduz de modo vivo as emoções e que geralmente vem acompanhada do ponto de exclamação e, em Bechara (2006) que 
corrobora a proposição dos autores anteriores, reconhecendo que as interjeições são expressões que traduzem os estados emotivos acompanhados de tom melódico exclamativo, podendo "assumir papel de unidades interrogativo-exclamativas e de certas unidades próprias do chamamento, chamadas vocativo, e ainda por unidades verbais como é o caso do imperativo". (BECHARA 2006, p. 330-331)

\section{Metodologia}

A realização do trabalho compreende três momentos. No primeiro, com o objetivo de evidenciar a formação da microconstrução olha já, sua compreensão global e relações de ligações simbólicas, efetuam-se as análises da forma por meio da estrutura sintática e do significado por meio da estrutura semântica e abordagens pragmática e discursiva funcional, como propõe Croft (2007). No segundo, propõe-se uma sugestão de composição da microconstrução e outra de sua atuação na língua, sob a luz de Fillmore et al (1988); Cunha e Cintra (1985) e Bechara (2006). No terceiro, examina-se a possibilidade da existência de outras microconstruções compostas pela mesma regra de formação de olha já, observando a produtividade do padrão.

\section{Resultados}

\subsection{Análise Sintática de olha já}

Observando a expressão olha já apartada do contexto, percebe-se, pela flexão do verbo (olha), que a sentença pode estar tanto no presente do indicativo, quanto no imperativo afirmativo. No primeiro caso, tem-se um sujeito oculto/elíptico representado pela terceira pessoa do singular (Ele(a) olha já); no segundo, evidenciase uma ordem dada à segunda pessoa do singular (Olha já tu). Sobre o verbo, destacase, ainda, sua função perceptiva, lembrando que as ações descritas por verbos sensoriais sempre requerem partes específicas do corpo referentes aos cinco sentidos, 
no caso da microconstrução, privilegiam-se os olhos (olha). Segundo Teixeira (2015), os verbos de percepção,

de uma maneira geral, são estudados a partir da temática da marcação do discurso, da evidencialidade, da projeção metafórica, da focalização, tendo como base a consideração cognitivista de que o sistema conceptual humano é fundamentado em suas experiências cotidianas e, portanto, o corpo, as partes do corpo ou a remissão por inferência ao corpo servem de referência para construir significados nas línguas. No contínuo de extensões, tais verbos passam a ser utilizados para reter a atenção do interlocutor de forma que este escute, olhe, veja o que o falante quer dizer, qual sua intenção ao fazer determinada afirmação ou emitir determinada opinião, tendo em vista conquistar sua concordância (TEIXEIRA 2015, p. 245).

Quanto à predicação, o verbo olhar, normalmente, comporta-se como transitivo direto, transitivo indireto ou pronominal; porém, na sentença em análise, atua como verbo intransitivo, seguido de um advérbio. Observam-se as atuações rotineiras do verbo olhar:

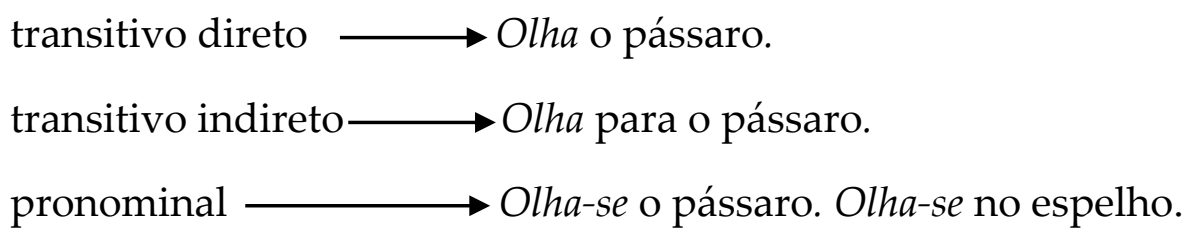

Observa-se que na microconstrução olha já o verbo perde suas propriedades características e não seleciona argumento. O segundo elemento constituinte da microconstrução é o advérbio marcador de tempo já, que, normalmente assinala significados como de imediato, prontamente, neste instante, agora, logo. Com base nesses sentidos, infere-se que a microconstrução é empregada para chamar a atenção a algo que não estava sendo visto/olhado e o vocábulo já cumpre a função de chamar a atenção para prontamente, de imediato, ser olhado. 
As observações sintáticas realizadas até aqui, permitem as seguintes considerações:

a) olha já é formada por um verbo de percepção (olhar), que regularmente é transitivo, porém se comporta como intransitivo na construção;

b) a flexão do verbo (olha) permite compreender a terceira pessoa do discurso (ele(a)) do presente do indicativo ou a segunda do singular (tu) do modo imperativo afirmativo;

c) o marcador de tempo já, chama a atenção para visão imediata de algo que não estava sendo visto.

A partir das considerações acima, definem-se as seguintes composições ${ }^{1}$ :

Quadro 1 - Perspectivas de composição sintática da microconstrução olha já.

\begin{tabular}{|c|c|c|c|}
\hline \multicolumn{3}{|c|}{ Composição I } \\
\hline 1 & & Olha & já \\
& suj. oculto (ele(a)) & verbo perc. intr. - pres. ind. & adv. mon. \\
\hline & Composição II & jha & suj. oculto $(t u)$ \\
\hline
\end{tabular}

Fonte: elaborada pela autora

${ }^{1}$ Abreviaturas utilizadas nas designações dos elementos das composições: suj. sujeito; perc. perceptivo; intr. intransitivo; pres. presente; ind. indicativo; adv. advérbio; mon. monossílabo; imp. imperativo; afirm. afirmativo. 


\subsection{Análise Semântica de olha já}

Segundo Croft (2007), o significado dos componentes de uma construção compreende não só as propriedades da situação descrita pelo enunciado, mas também, as propriedades do discurso em que o enunciado está inserido.

Considerando a importância do contexto na análise semântica, apresenta-se o texto I, fragmento de um diálogo entre dois amigos que residem em uma cidade no interior do Amazonas, presente em um artigo ${ }^{2}$ que é fruto de projeto de pesquisa do Instituto Federal de Educação Ciência e Tecnologia do Amazonas IFAM, o qual trata de palavras e expressões da língua local dessa região.

\section{Texto I - Feira de expressões}

“O ambiente é numa feira, de produtos em geral. Dois amigos se encontram e começam a conversar, botando os babados em dia.

Ela - Oi mano!

Ele - Oi mana!

Ela - Tudo beleza contigo?

Ele - Tudo bem, só na maciota.

Ela - Ah, que bom. E aí, e os babados?

Ele - Vichi, tenho rolos pra te contar!

Ela - Adoooro! Mas tá tri quente aqui, bora ainda ali comprar um din-din pra gente chupar enquanto conversa.

Ele - De rocha.

Ela - Mas e aí, o que tu tem pra me contar?

Ele - Tu nem sabe! Um dia desses um galeroso não roubou meu celular?!

Ela - Olha já! ${ }^{3}$ Quando foi isso? Onde?

Ele - Foi semana passada quando eu tava voltando pra casa a pé. E era um curumim mana, parecia que tava era chapado. Veio pra cima de mim com uma faca pedindo meu celular. Ela - Pela madrugada! E o que tu fizeste?

Ele - Eu entreguei né, senão ele ia me furar com a faca."

(...)

Autores: Breno Cunha Barbosa e Renata Cazemiro Ferreira

(ALVES; SIQUEIRA, 2012, p. 4-5)

\footnotetext{
${ }^{2}$ Disponível em: http://propi.ifto.edu.br/ocs/index.php/connepi/vii/paper/view/3953/1983.

3 (itálico nosso)
} 
No texto, a sentença - Olha já! Quando foi isso? Onde? é proferida pela interlocutora após ouvir a informação de seu interlocutor sobre o roubo do celular dele. Considerando-se o sentido do verbo olhar como enxergar, nota-se que os questionamentos que acompanham a microconstrução Olha já! não são coerentes com os significados dados às partes composicionais na análise sintática, pois o presente do indicativo ou imperativo afirmativo levam à compreensão de que existe algo a ser visto naquele presente momento e o advérbio de localização temporal já corrobora esse sentido. Se a ação (roubar) tivesse, de fato, acontecido no momento da enunciação ou no futuro, não haveria, no enunciado da interlocutora, a necessidade da pergunta relativa ao tempo passado, com verbo ir no pretérito: Quando foi isso? E nem o questionamento do lugar: Onde?, que conduz o pensamento a outro lugar, diferente daquele do momento em que o diálogo ocorre.

Embora a microconstrução em estudo tenha em sua constituição um advérbio considerado marcador de tempo, ela apresenta independência de referência temporal. Alguns estudos demonstram que na língua em uso, isso é normal acontecer. A linguista funcionalista Neves $(2010,2011)$ propõe que os advérbios de tempo e lugar, diferente do que apresenta a gramática convencional, não são modificadores do verbo e, sim, apresentam um comportamento sintático heterogêneo.

Os questionamentos relativos ao tempo passado e o valor atribuído ao já no contexto do diálogo revelam que o significado da microconstrução olha já não é literal como previsto na análise sintática. Os questionamentos da interlocutora denotam interesse em detalhes de algo já ocorrido. Essas reflexões permitem definir a pessoa do discurso como tu e o verbo no modo imperativo afirmativo, levando a descartar a hipótese de terceira pessoa do singular e a do presente do indicativo na composição da microconstrução.

A transgressão dos significados do verbo e do advérbio na análise sintática permite a observação do emparelhamento da forma e do significado com atuação 
arbitrária. Esse fenômeno e o fato de o significado da microconstrução olha já se tornar compreensível somente após as inferências do contexto corroboram os conceitos de construção dos linguistas mencionados na base teórica.

Observa-se ainda, que na sentença - Olha já! Quando foi isso? Onde? a microconstrução em estudo ocupa uma posição isolada dos demais elementos sintáticos, caso seja suprimida, a comunicação não é afetada.

O posicionamento da expressão Olha já! no início da sentença, mostra o verbo (olha) atuando como marcador discursivo, invocando o interlocutor para o momento da fala e, ao mesmo tempo, exibe os sentimentos de surpresa e espanto, motivados pelo enunciado anterior do interlocutor (ele).

Os textos II, III, IV e V são guias de dialetos de expressões regionais do Amazonas elaborados por falantes e veiculados em sites na internet. Esses textos apresentam definições da microconstrução olha já; explicam-na, até mesmo, como sinônimo de outra construção gramatical.

\section{Texto II - Aulas de amazonês}

Figura 4 - Olha ját! como expressão de indignação.

B https://viajeamazonas.com/blog/manaus-amazonas-aulas-de-amazones/
algo chamado tesão de mormaço. Auto-explicativo.
AGORINHA - Diferentemente do uso no sudeste, agorinha quer dizer "há alguns
segundos", referindo-se ao passado e não ao futuro. "Ela estava aqui agorinha, mas
sumiu".
OLHA JÁ! - Expressão de indignação correspondente a "Mas que abuso!".
"E aí, gata, me dá um beijo?" "Mas, olha já esse aí...Te manca!"
MANO(A) - Tratamento carinhoso entre conhecidos ou não. Muito usado para fazer
perguntas e pedidos. "Mana, faz um favor pra mim". "E aí, tudo bem, mano?"
Fonte: https://viajeamazonas.com/blog/manaus-amazonas-aulas-de-amazones/

\footnotetext{
${ }^{4}$ Destaque (em amarelo) no texto II nosso.
} 
O texto II confere à microconstrução olha já a noção de indignação e atribui a ela a equivalência da construção “Mas que abuso!”. O exemplo de diálogo apresentado, ratifica a importância do contexto para que a expressão seja compreendida:

"E aí, gata, me dá um beijo?"

"Mas, olha já esse aí... Te manca!"

Ao pedido de um beijo, tem-se uma resposta com sentido negativo: "Mas, olha já esse aí... Te manca!", em que a microconstrução olha já se encontra, dessa vez, no meio da frase e não é acompanhada por um ponto de exclamação. Nota-se, no entanto, no destaque em amarelo (nosso) no texto, que o autor apresenta a microconstrução com o ponto de exclamação. É provável que ele tenha escolhido pontuar somente no final do exemplo para não comprometer o conteúdo que intenciona expressar, para não chamar atenção apenas para olha já. Observa-se no texto II a microconstrução posicionada na frase de maneira diferente da apresentada no texto I, no entanto, com sentido próximo ao conferido a ele, pois o contexto deixa claro os sentimentos de surpresa e espanto da interlocutora gata.

\section{Texto III - Dialeto amazonense - o amazonês ilustrado ${ }^{5}$}

Figura 5 - Expressão amazonense Má rapáz! (rapá) explicada com Olha já!

1. Amazones-llustrado-21.jpg $(646 \times+$

$\leftarrow \rightarrow O$ in B https://marcuspessoa.com.br/wp-content/uploads/2013/10/Amazones-llustrado-21.jpg

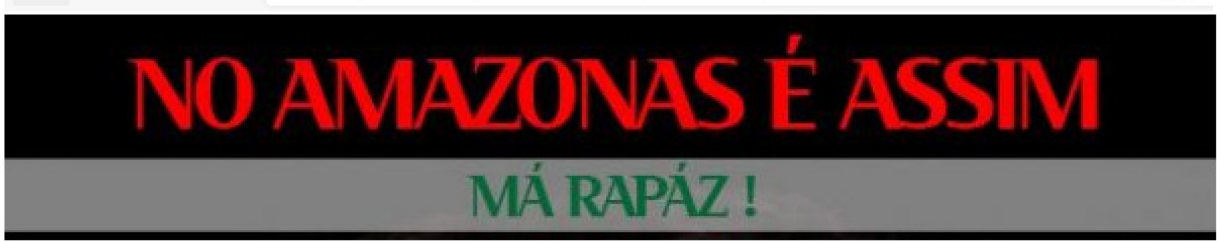

MÁ RAPÁZ!

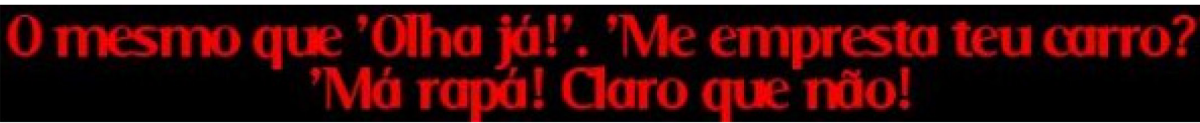

O mesmo que ‘Olha já!'. ‘Me empresta teu carro?'

'Má rapá! Claro que não!

Fonte: https://marcuspessoa.com.br/dialeto-amazonense-o-amazones/

\footnotetext{
${ }^{5}$ No texto, suprimiu-se uma imagem, destacando-se apenas a escrita.
} 
O texto III define a microconstrução gramatical Má rapáz (rapá)! com a microconstrução Olha já!. Para análise, transcreve-se a sentença com substituição de Má rapá! pela microconstrução olha já!

'Me empresta teu carro?'

‘Olha já! Claro que não!

Assim como no texto II, Olha já! é utilizada na formação de enunciado como resposta negativa a um pedido. A microconstrução empregada, com certa ênfase/dramaticidade, anterior à sentença negativa Claro que não!, cumpre o papel de anunciar que aquilo que foi solicitado extrapola a normalidade, revelando que o ato da solicitação do empréstimo do carro é abusivo. O uso da microconstrução no texto III corroboram os sentimentos de indignação e abuso sugeridos pelo autor do texto II e, expressam também, a surpresa e o espanto do dono do carro.

Convém expor que a sentença de sentido negativo como "Claro que não!” presente no texto III, pode revelar o alto grau de interação cognitiva e interpessoal existente entre os interlocutores, papel importante na realização de ações com função pragmática-discursiva.

\section{Texto IV - No Amazonas é assim: Márrapá!}

Figura 6 - Expressão amazonense Márrapá! explicada com “Olha já!”6

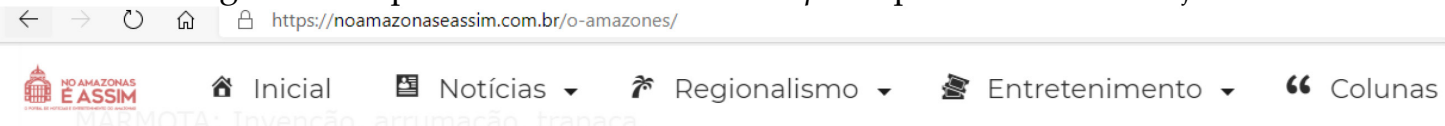

MAROMBA : Jirau elevado, feito com troncos ou madeira, para deixar a salvo animais domésticos, plantas e pertences dos ribeirinhos, durante as enchentes.

MÁRRAPÁ!: O mesmo que "Olha já!" .

MARRETEIRO: Vendedor ambulante.

MAS!:Pronuncia-se "Mách): . Interjeição de ênfase.

Fonte: https://noamazonaseassim.com.br/o-amazones/

\footnotetext{
${ }^{6}$ Destaque (em amarelo) no texto IV nosso.
} 
Assim como no texto III, o texto IV também apresenta a construção Márrapá! ${ }^{7}$ como sinônimo de Olha já!, o que permite considerar que a microconstrução olha já é muito popular entre os falantes da região, a ponto de ser utilizada na explicação de outra construção amazonense.

\section{Texto V - Palavras e Expressões Regionais do Amazonas}

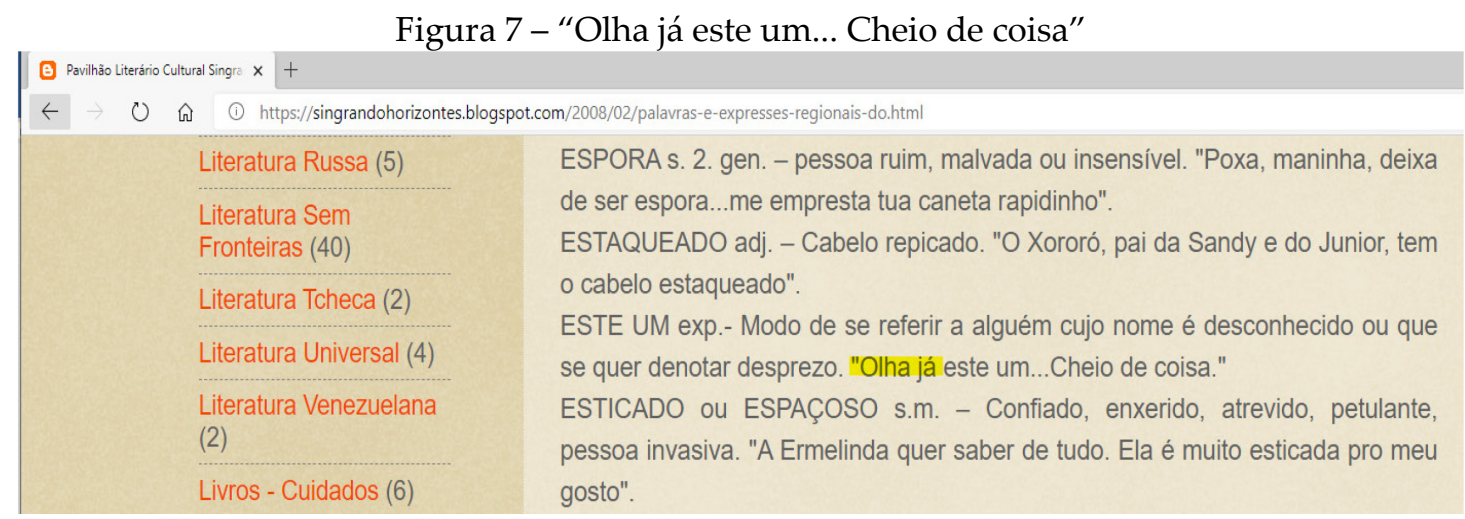

Fonte: https://singrandohorizontes.blogspot.com/2008/02/palavras-e-expresses-regionais-do.html

$\mathrm{O}$ texto $\mathrm{V}$ também se propõe a descrever significados de expressões regionais do Amazonas. Apresenta a microconstrução olha já na exemplificação de uso do termo este um: "Olha já este um... Cheio de coisa."

$\mathrm{O}$ texto $\mathrm{V}$ não apresenta o enunciado anterior à sentença que contém a microconstrução olha já, porém, nota-se que é proferida para mostrar que o comportamento de alguém não é o esperado e vem associada ao termo (este um) que, segundo o autor do texto, é utilizado para denotar desprezo. Como no texto II, no exemplo, não apresenta sinal exclamativo após a microconstrução.

\footnotetext{
${ }^{7}$ Registra-se o traço de oralidade expresso por meio de alterações ortográficas em Má rapáz! e Má rapá! no texto III e Márrapá! no texto IV.
} 


\section{Texto VI - Olha já (então)!}

Figura 8 - Expressão Olha já (então)! como interjeição de indignação

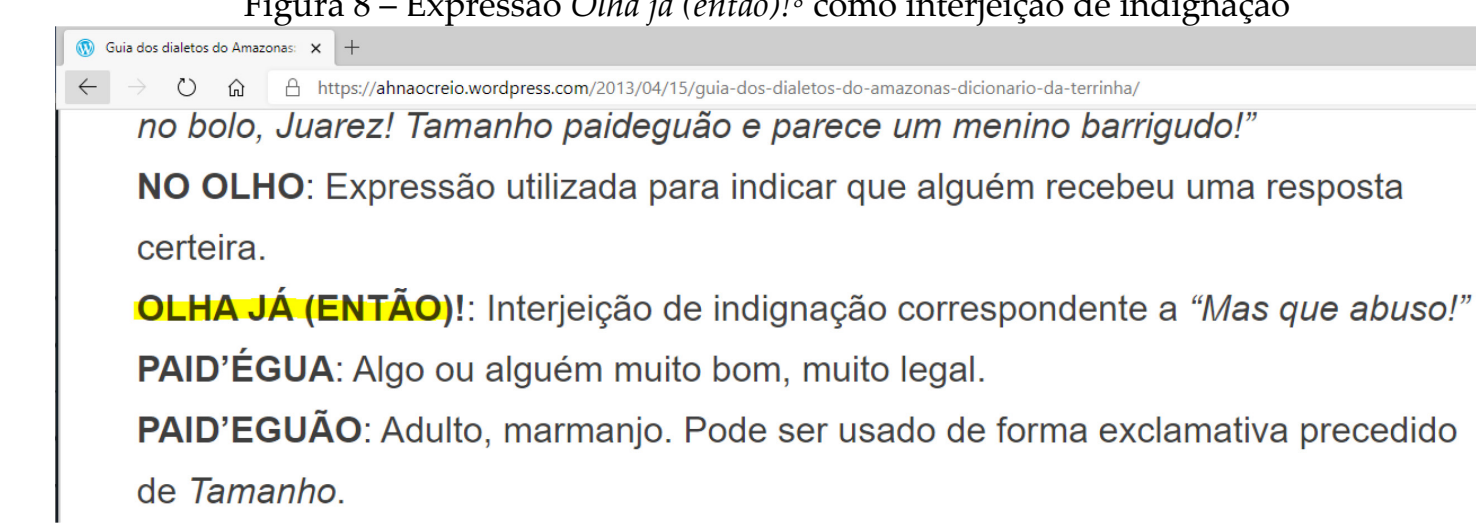

Fonte: https://ahnaocreio.wordpress.com/2013/04/15/guia-dos-dialetos-do-amazonas-dicionario-daterrinha/

O autor do texto VI apresenta olha já (então)! e a define com o mesmo sentido apresentado para a microconstrução no texto II: “Mas que abuso!”. Infere-se que o falante/autor tenha reconhecido um desgaste no uso de olha já e, por isso, tenha conferido à microconstrução o acréscimo de então, no intuito de recuperar sua expressividade. O advérbio então, colocado entre parênteses pelo autor do texto, permite inferir, também, que a microconstrução com ou sem esse vocábulo mantém o mesmo valor.

Diante do exposto, observa-se que a microconstrução olha já é muito utilizada na comunicação informal no Amazonas, tendo em vista o seu emprego para explicar outra microconstrução e pela presença de uma variante como olha já (então)! nos guias de dialeto de expressões regionais.

Os textos mostram a microconstrução posicionada tanto no início como no meio da sentença, conferindo ao enunciado um tom dramático de surpresa, espanto e até de indignação. Caso a microconstrução seja suprimida das sentenças, observa-se perda de ênfase pragmática e não de sentido.

\footnotetext{
${ }^{8}$ Destaque (em amarelo) no texto VI nosso. 


\subsection{Relações de ligações simbólicas entre forma e significado}

Considerando que a representação de uma construção inclui relações de correspondência entre a forma e o significado, sintetiza-se, neste item, a contribuição dos elementos e dos componentes para o sentido global da construção olha já.

O verbo olhar é compreendido pela ação da fixação dos olhos em algo e o modo imperativo normalmente se refere a conselho ou à advertência. No entanto, dentro da interação comunicativa, o verbo na microconstrução olha já se despe dessas funções habituais e atua como componente de feedback emotivo. Como se observam nos exemplos, a microconstrução é sempre empregada como reação a algo que não era esperado. O advérbio já, diferente de seu sentido convencional de tempo, atua de forma incisiva para o fechamento desse feedback emotivo.

Destaca-se também como elo simbólico a presença da criatividade argumentativa, expressa pelo advérbio monossílabo tônico (já) seguido do ponto de exclamação na maioria dos casos. Segundo Cunha e Cintra (1985), o valor melódico da exclamação só pode ser depreendido por meio do contexto, cabendo ao leitor "a tarefa, extremamente delicada, de interpretar a intenção do escritor; de recriar, com apoio em um simples sinal, as diversas possibilidades da inflexão exclamativa". (CUNHA; CINTRA 1985, p. 638). Na microconstrução, o uso de um vocábulo curto como o monossílabo já, marca uma intenção rápida e incisiva em torno do verbo olhar, contribuindo com a intencionalidade que o falante pretende expressar.

\subsection{Sugestão de composição e de atuação de olha já}

Após a observação da forma e do significado nos textos, define-se a seguinte composição para a microconstrução olha já: 
Quadro 2 - Composição sintática da expressão olha já.

\begin{tabular}{|c|c|c|}
\hline \multicolumn{3}{|c|}{ Composição sintática } \\
\hline Olha & já & adv. mon. \\
verbo perc. intr. - imp. afirm. & sujeito oculto $(t u)$ \\
\hline
\end{tabular}

Fonte: elaborada pela autora.

Embora olha já não seja uma expressão idiomática, apresenta traço de expressão idiomática de decodificação como a definida por Fillmore et al (1988), o que permite sugerir que a microconstrução apresenta característica de expressão idiomática.

Outro ponto a relevar é a atuação da microconstrução como interjeição. Embora, nem todos os exemplos com olha já tenham sido imediatamente acompanhados por ponto de exclamação, os significados apreendidos nas análises permitem observar na atuação da microconstrução o grito instintivo que traduz de modo vivo as emoções do falante, acompanhado do tom melódico que o imperativo confere ao verbo.

Com essas considerações, sugere-se que a microconstrução olha já atua nos textos como uma interjeição com estrutura idiomatizada, com função enfática que confere à comunicação um tom dramático de espanto, surpresa ou indignação.

\subsection{A produtividade da construção}

Analisa-se como produtividade, o potencial criativo da regra de formação da construção olha já, ou seja, verbo perceptivo intransitivo imperativo afirmativo + advérbio monossílabo. Nesse padrão, apresentam-se as seguintes composições: 
Quadro 3-microconstruções compostas pela regra de formação de olha já.

\begin{tabular}{|c|c|c|c|}
\hline \multicolumn{3}{|c|}{ Composição sintática } \\
\hline ord. & verbo perc. intr. - imp. afirm. & adv. monossílabo & sujeito oculto \\
\hline 1 & vê & lá & $(\mathrm{tu})$ \\
\hline 2 & olha & lá & $(\mathrm{tu})$ \\
\hline 3 & olha & só & $(\mathrm{tu})$ \\
\hline 4 & olha & bem & $(\mathrm{tu})$ \\
\hline 5 & escuta & só & $(\mathrm{tu})$ \\
\hline 6 & veja & bem & $(\mathrm{ele} / \mathrm{ela})$ \\
\hline
\end{tabular}

Fonte: elaborado pela autora.

As seis microestruturas selecionadas no quadro 3, assim como olha já, não denotam sentidos literais e, sim, sentidos atribuídos pela comunidade de fala. Para exemplificá-las, buscam-se fragmentos de textos literários dos séculos XVIII e XIX (1, 2) presentes no trabalho de Teixeira $(2015)^{9}$ e em canções brasileiras atuais $(3,4,5,6)$, como seguem:

1. (...) Eis aí te fez Cristo digno de levares a sua cruz e segui-lo; vê lá não faças pé atrás e acudas mais pela tua carne que pela tua alma e te furte o diabo o reino da glória. (...) (Apólogos morais - Texto crítico barroco, Nova floresta de Manuel Bernardes, sequência injuntiva, século XVIII) (TEIXEIRA, 2015, p. 212)

2. (...) - Acabo de dizer que sim. - E se não vieres.. - Farás o que entenderes.. - Olha lá.. - Estamos combinados, filha! Pois conto contigo. (...). (Romance As Memórias de um Condenado de Aluísio Azevedo, sequência injuntiva, século XIX) (TEIXEIRA, 2015, p. 252)

3.4. (...)

Olha só, meu amor (meu amor)

Nada disso faz sentido

\footnotetext{
${ }^{9}$ Teixeira (2015) apresenta em sua tese A construção verbal marcadora discursiva: uma análise centrada no uso um valioso estudo sobre construções gramaticais.
} 
Olha só, por favor (por favor)

Não duvide do que eu digo

Olha só, olha bem

Entre nós não há segredo, tudo bem! (...)

Grupo Rouge: Olha só ${ }^{10}$ (itálicos nosso)

5. Escuta só, vamos tentar (itálico nosso)

Pois diferenças todo mundo tem (...)

José Augusto: Escuta són ${ }^{11}$

(...)

6. Veja bem, foi você (itálico nosso)

A razão e o porquê

De nascer essa canção assim (...)

Roberto Carlos: Nossa canção ${ }^{12}$

Observa-se o aspecto produtivo do padrão no PB por meio das presenças das microconstruções olha só (3) e olha bem (4) na mesma canção, assim como os títulos das canções Olha só (Grupo Rouge) e Escuta só (José Augusto) realizados com microconstruções.

Convém elucidar que não se constitui objetivo deste trabalho esgotar as chances de composição com verbos perceptivos na língua portuguesa e, sim, apresentar microconstruções que corroborem a produtividade do padrão estabelecido para a composição olha já.

\section{Considerações finais}

O estudo, sob a luz de pressupostos teóricos da Gramática de Construções, proporcionou uma visão ampla dos aspectos que compõem o significado da microconstrução olha já. A análise da microconstrução com base nas estruturas 
sintática e semântica, consideradas por Croft (2007) componentes constituintes da anatomia de uma construção gramatical, contribuiu para o entendimento global da microconstrução; instigando, ainda, à propositura de uma sugestão de sua atuação na língua. $\mathrm{O}$ estudo possibilitou, também, a constatação da existência de outras microconstruções com a mesma composição de olha já, atestando a produtividade do padrão.

Quanto ao uso da microconstrução olha já no estado do Amazonas, observa-se que sua presença em guias de dialetos de expressões regionais veiculados em vários sites na internet, inclusive explicando outra construção, por si só, atesta a produtividade de uso da microconstrução na região.

Por fim, espera-se que este modesto trabalho possa inspirar a propositura de mais estudos voltados à língua portuguesa realizada na região do Amazonas.

\section{Agradecimento}

À profa. Dra. Sueli Maria Coelho pela rica disciplina de Gramática de Construções ministrada em 2018 no Poslin - UFMG, a qual fez despertar meu interesse por construções gramaticais.

\section{Referências Bibliográficas}

ALVES, J. R.; SIQUEIRA G. A. M. Semântica Mauesense em foco. In: VII CONGRESSO NORTE NORDESTE DE PESQUISA E INOVAÇÃO. Palmas, 2012. Disponível em: http://propi.ifto.edu.br/ocs/index.php/connepi/vii/paper/view/3953/1983. Acesso em: 15 set. 2020.

AMAZONAS by viverde blog. 2007.1. Amazonas - Aulas de amazonês. Autor desconhecido. Disponível em: https://viajeamazonas.com/blog/manaus-amazonasaulas-de-amazones/. Acesso em: 14 out. 2020.

BECHARA, E. Moderna gramática portuguesa. 37. ed. Rio de Janeiro: Nova Fronteira/Lucerna, 2006. 
BENTES, N. 2013.4. Guia dos dialetos do Amazonas: Dicionário da Terrinha. Disponível em: https://ahnaocreio.wordpress.com/2013/04/15/guia-dos-dialetos-doamazonas-dicionario-da-terrinha/. Acesso em: 14 out. 2020.

BOAS, H. C. Cognitive Construction Grammar. In: HOFFMANN, T.; TROUSDALE, G. (ed.) The Oxford Handbook of Construction Grammar. Oxford: Oxford University Press. 2013. p. 233-254. DOI https://doi.org/10.1093/oxfordhb/9780195396683.013.0013

CROFT, W. A. Construction grammar. In: GEEREARTS, D.; CUYCKENS, H. The Oxford Handbook of Cognitive Linguistics. Oxford: Oxford University Press, 2007, p. 463-508.

CUNHA, C.; CINTRA, L. F. L. Nova gramática do português contemporâneo. 2. ed. 22. Rio de Janeiro: Nova Fronteira, 1985.

FILLMORE, C. J.; KAY, P.; O'CONNOR, M. C. Regularity and Idiomaticity in Grammatical Constructions: The Case of Let Alone. Language. Vol. 64, n. 3, p. 501-538, 1988. Disponível em: http://links.jstor.org/sici?sici=00978507\%28198809\%2964\%3A3\%3C501\%3ARAlIGC\%3E2.0.CO\%3B2-Y. Acesso em: 15 set. 2020.

GOLDBERG. A. E. Constructions: a construction grammar approach to argument structure. Chicago: The University of Chicago Press, 1995.

NEVES, M. H. M. Ensino de língua e vivência de linguagem: temas em confronto. São Paulo: Contexto, 2010.

NEVES, M. H. M.Gramática de usos do português. São Paulo: Unesp, 2011.

PAVILHÃO literário cultural singrando horizontes. 2008.02. Palavras e Expressões Regionais do Amazonas. Autor desconhecido. Disponível em: https://singrandohorizontes.blogspot.com/2008/02/palavras-e-expresses-regionaisdo.html. Acesso: em 14 out. 2020.

PESSOA, M. 2013.10. Dialeto amazonense - o amazonês ilustrado. Disponível em: https://marcuspessoa.com.br/dialeto-amazonense-o-amazones/. Acesso em: 14 out. 2020.

SOUZA, S. A. F. 2013.02. Dicionário de Amazonês. Disponível em: https://noamazonaseassim.com.br/o-amazones/. Acesso em: 14 out. 2020. 
TEIXEIRA, A. C. A construção verbal marcadora discursiva VLocmd: uma análise funcional centrada no uso. 2015. 297 f. Tese (Doutorado em Estudos de Linguagem. Área de Concentração: Língua Portuguesa) - Instituto de Letras, UFF, Niterói, 2015. Disponível em: https://app.uff.br/riuff/bitstream/handle/1/10301/Tese\%20Ana\%20Cláudia\%20Macha do\%20Teixeira.pdf?sequence=1\&isAllowed=y. Acesso em: 22. nov. 2021. 